\title{
Urbanisation and health
}

\author{
Richard Godfrey and Marlene Julien
}

\begin{abstract}
The effect on health of urbanisation is two-edged. On the one hand, there are the benefits of ready access to healthcare, sanitation, and secure nutrition, whilst on the other there are the evils of overcrowding, pollution, social deprivation, crime, and stress-related illness. In less developed countries, urbanisation also opens the door to 'western' diseases, including hypertension, heart disease, obesity, diabetes and asthma. Here we review some of the health-related aspects of urbanisation, and comment on strategies designed to improve urban health. Because there is such a clear divide between the long process of urbanisation in industrialised western nations and the relatively recent explosive expansion in resource-poor countries, they are discussed separately.
\end{abstract}

KEY WORDS: developing countries, healthy cities, rural-urban migration, urban health, urbanisation

The world has experienced unprecedented urban growth over the past 200 years. In 1800, only 3\% of the total population lived in urban areas. By 1900 this had grown to $14 \%$ (but had hardly changed in Africa). By the year 2007 more than $50 \%$ of the world's total population will be urbanised, with the fastest rate of change in Africa. ${ }^{1}$ Globally the growth rate of urbanisation (urban share of total population per year) is estimated at $0.8 \%$. In Sub-Saharan Africa it is $1.6 \%$. Gigantic mega-cities with populations above 15 million now exist, or will soon exist, in every continent except Europe (Fig 1). ${ }^{2}$

There are 411 cities in the world with populations above 1 million, and together these cities are home to $39 \%$ of the global population. The high rates of urbanisation previously seen in the most developed countries are now being rapidly overtaken in resource-poor countries. Data from the United Nations Centre for Human Settlements illustrate the trends and also show the wide range of income available to municipal authorities as they grapple with accommodating huge numbers of new urban dwellers (Table 1). It is no surprise that between $30 \%$ and $60 \%$ of people in the large cities of poor countries live in conditions of abject poverty in slums, without access to piped water or adequate sanitation. ${ }^{3}$

\section{Definition of urbanisation}

There is no agreed definition on what constitutes an urban environment. Some countries regard any town with a population of more than 2,500 as urban, others set a minimum of 20,000. Definitions based on population size do not convey important factors such as population density, the availability of healthcare, or the standard of infrastructure. From a health point of view, these are much more important than sheer numbers. Urbanisation as a general all-embracing term also fails to identify the widely different patterns of social groupings and movements of people within large towns and cities (compare the garden suburbs of London with some of the more central boroughs).
Richard Godfrey MD FRCP, Health Advisor

Marlene Julien MB ChB, Health Volunteer

Merlin, London

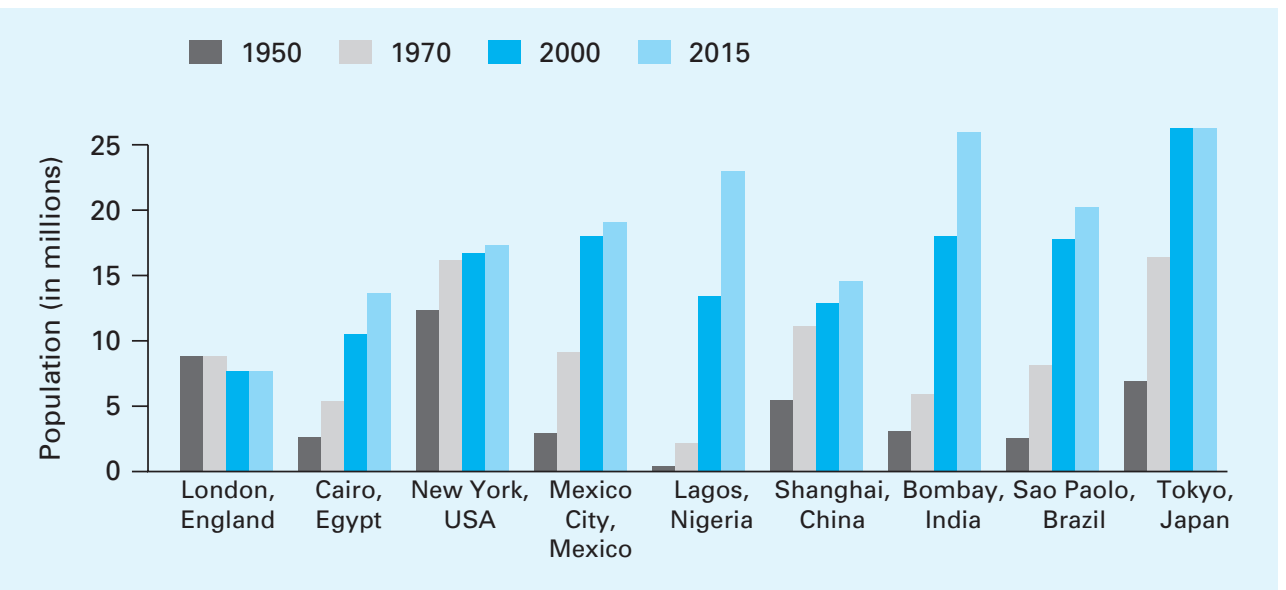

Fig 1. Growth of urban agglomerations, 1950-2015 (from Ref 2). 


\section{Key Points}

Health problems associated with urbanisation depend on the drivers causing people to migrate to towns, the economic background, and the adequacy of the urban infrastructure to cater for increased numbers

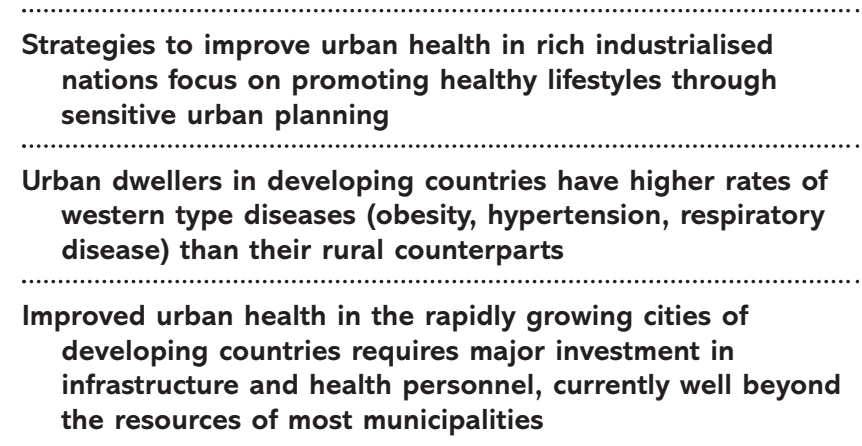

Rural-urban migration can be slowed but seldom halted, and almost never reversed

\section{Urbanisation in industrialised western countries}

Urbanisation has been going on in a small way since the beginning of recorded history, but it was with the industrial revolution, starting in the mid-eighteenth century, that large-scale migration from country to town began. Most large British towns have seen several fairly distinct phases over the past 200 years. ${ }^{4}$ During the industrial revolution there was uncontrolled migration from surrounding rural areas, leading to congested housing and rapid deterioration to slum conditions - save for the grand buildings of the city centres. Health statistics from that period reflected the markedly worse situation of urban populations compared with those in the rural areas so recently left behind. For example, infant mortality in England and Wales between 1889 and 1891 was 2.2 times higher in urban areas than in rural ones. ${ }^{5}$ There were frequent outbreaks of dysentery, typhoid, cholera, pneumonia and meningitis. Tuberculosis was wide-

Table 1. Population predictions and revenue available to urban municipalities.

\begin{tabular}{|c|c|c|c|c|c|}
\hline Countries & $\begin{array}{c}\text { Population } \\
2001 \\
\text { (millions) }\end{array}$ & $\begin{array}{c}\text { Percentage } \\
\text { of } 2001 \\
\text { population } \\
\text { urbanised }\end{array}$ & $\begin{array}{l}\text { Predicted } \\
\text { population } \\
\text { by } 2020 \\
\text { (millions) }\end{array}$ & $\begin{array}{l}\text { Predicted } \\
\text { percentage } \\
\text { of } 2020 \\
\text { population } \\
\text { urbanised }\end{array}$ & $\begin{array}{c}\text { Annual } \\
\text { revenue per } \\
\text { capita } \\
\text { available to } \\
\text { municipal } \\
\text { authorities }\end{array}$ \\
\hline Sub-Saharan Africa & 611 & $34 \%$ & 952 & $46 \%$ & $\$ 14$ \\
\hline Arab states & 270 & $56 \%$ & 395 & $66 \%$ & $\$ 46$ \\
\hline Asia and Pacific & 3,515 & $35 \%$ & 4,298 & $46 \%$ & $\$ 153$ \\
\hline $\begin{array}{l}\text { Highly industrialised } \\
\text { countries }\end{array}$ & 597 & $80 \%$ & 649 & $84 \%$ & $\$ 2,906$ \\
\hline $\begin{array}{l}\text { Latin America and } \\
\text { Caribbean }\end{array}$ & 521 & $75 \%$ & 665 & $81 \%$ & $\$ 87$ \\
\hline $\begin{array}{l}\text { Economies in } \\
\text { transition }\end{array}$ & 543 & $70 \%$ & 541 & $78 \%$ & $\$ 275$ \\
\hline
\end{tabular}

spread. Nutrition was often poor. Only the continued migration from rural areas sustained and increased the population of the rapidly growing towns.

The hygienist movement and the development of public health started in Britain around 1860. Clean water and sanitation gradually turned the adverse health statistics around, and towns and cities started to become fashionable places for the growing middle classes. Here were the best hospitals and schools, and the best chances of profitable employment. The new urban immigrants lived in ever-expanding green suburbs, leaving slums and substandard housing more or less untouched nearer to city centres. In the latter part of the nineteenth century, increasing social awareness at last led to slum clearance and various experiments to provide better housing for the still growing urban populations.

Now, at the start of the twenty-first century, many large towns and cities have yet further elements which contribute to a patchwork of widely different social and physical structures all within a few kilometres of one another. These latest elements include inner-city regeneration projects, which often lead to exclusive housing beyond the reach of all but the very privileged. At another level, increasing numbers of immigrants settle in well defined areas with varying degrees of integration. Most of the largest cities in industrialised countries have 'quarters' where different ethnic groups develop remarkable homogeneity and continuation of their indigenous culture.

\section{Health in a modern western city}

Every group within the social, cultural and physical patchwork of a modern city tends to have has its own health-related problems and characteristics. The problems of the socially marginalised (alcoholism, drug dependency, crime, homelessness) are more concentrated in cities. Many less obvious but still serious health problems are not far below the surface (Table 2).

Sexually transmitted disease (STD) is widespread among the young: for example, $40 \%$ of sexually active teenage girls had an STD in a study reported from Atlanta, ${ }^{6}$ with gonorrhoea showing a marked rise in prevalence in the past five years. Tuberculosis, until 1980 showing a steady decline, has now emerged as a significant problem in some of London's boroughs. Its presence often reflects poor social conditions among immigrant groups. ${ }^{7}$ Stress-related disorders and depression have steadily increased in modern cities. ${ }^{8}$ There are also largely hidden problems associated with loneliness and isolated old age perhaps the most startling recent example was the huge number (more than 12,000) of elderly people living alone in Paris who 
succumbed to hyperthermia and dehydration during the heat wave of August 2003. Many bodies were buried in paupers' graves because no relatives came forward. ${ }^{9}$

\section{Urbanisation in resource-poor countries}

The problems of urbanisation in affluent societies pale beside those of Africa, South East Asia and South America. Here the rates of urban migration in some countries during the last 50 years have accelerated so much as to overwhelm the infrastructure, with the result that many people live in conditions of squalor. Slums, often no more than small rooms separated by scraps of wood, corrugated metal or plastic sheets, are to be found in all large cities of these continents. Often there is no sanitation, piped water, or rubbish disposal. In Addis Ababa, there are large areas of slums where young girls of 12 conduct commercial sex behind a cardboard screen in the corner of a squalid room filled with relatives and other young children.

The driving forces behind this massive urban migration can be summarised as: ${ }^{10}$

Forced move ('push factors')

- drought, floods, earthquake

- war, revolution, and civil disturbance

- economic disaster, famine, loss of job.

Economic and cultural factors ('pull factors')

- marriage

- low income and high aspirations

- desire for better education, healthcare, housing

- job opportunities in industry (especially mining in Africa)

- pull effect of relatives in towns

- dissatisfaction with traditional lifestyle.

Interestingly, the dynamics of urban migration in Africa have varied widely from country to country over the last 50 years. ${ }^{3}$ The countries where urbanisation was the most rapid were primarily those where economic development took place, acting as a pull factor. Examples were oil exporting countries (Gabon, Libya, Cameroon, Algeria, Nigeria), mining countries (Botswana, Zambia), and countries relying on small industries (Tunisia) or agro-business (Côte d'Ivoire). In other cases, push factors were more important, such as drought in Mauritania, or the civil war in Mozambique.

\section{Effect of fast-growing cities on health in resource-poor countries}

Despite the appalling living conditions of many migrant workers, most available data suggest that the health of people in the towns of resource-poor countries is better than that of their rural counterparts. In some countries the difference is striking, for example in Senegal where the relative risk of rural to urban underfive mortality has remained consistently high (around 1.85 ) for many years. A more typical figure is a $20 \%$
Table 2. Some health problems in the cities of industrialised countries.

1 Social breakdown

Isolation, loneliness, depression

Sexually transmitted disease

Alcohol and drug dependency

Homelessness

2 Pollution

Smoke, exhaust fumes

Noise pollution, light pollution

Passive smoking

Previous industrial waste, asbestos

'Sick building syndrome'

3 Accidents and violence

Transport accidents

Criminal violence

Accidents at work

4 Poor nutrition

Poverty

Obesity and associated diseases

Hypertension

5 Lifestyle hazards

Lack of exercise (early onset type 2 diabetes)

Anxiety, long working hours, hyper-competitiveness

6 Migrant population

Changing patterns of disease, eg tuberculosis

Unequal access to health and education

difference in overall mortality rates in favour of urban populations. The chief reason for the advantage is better access to health services which tend to be centralised in the towns and cities of developing countries. ${ }^{11}$

Despite this surprising picture in favour of the urban dweller, there are, of course, many places in many poorer countries where health is directly severely affected by urban living. ${ }^{12}$ Child mortality is high in the slums of Haiti, the Philippines, and many Brazilian and Indian cities. In these places, child mortality significantly outstrips corresponding rural child mortality,

\section{Fig 2. Addis Ababa.}

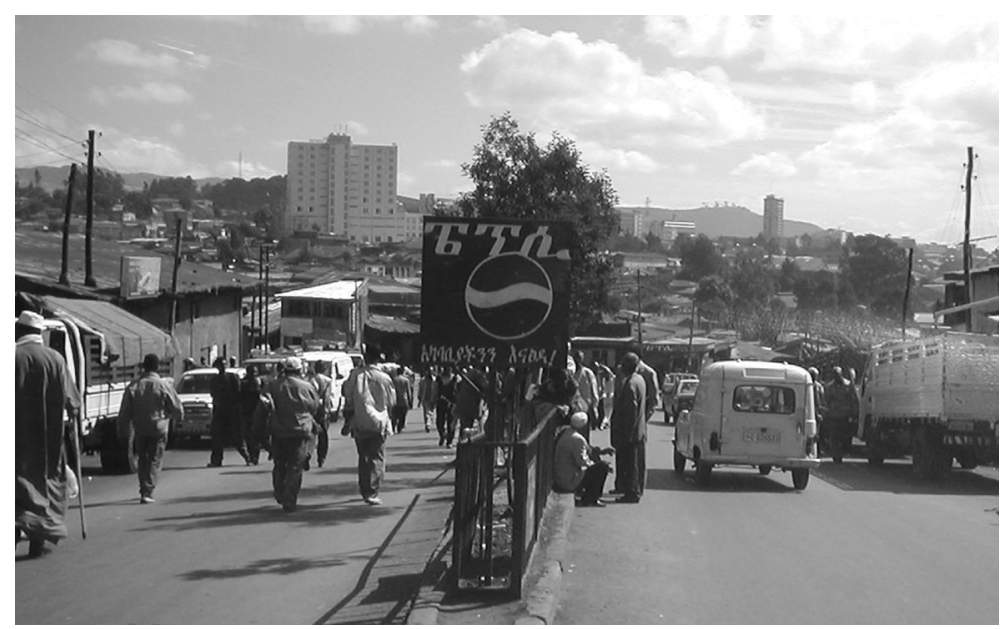


mainly due to a high incidence of water-borne infection in the slums. In Kenya, mortality among the under-fives has increased by $44 \%$ since 1988 , due to a combination of increasing poverty and HIV/AIDS. A recent survey revealed an appalling under-five mortality rate of 254 per 1,000 in a slum of Nairobi. ${ }^{13}$ The conditions which show significantly higher prevalence in the cities of resource-poor countries are listed in Table 3.

Some of the most striking differences between urban communities and their rural counterparts have arisen with the HIV/AIDS pandemic. The HIV prevalence rates quoted for different countries are frequently misleading, in that they fail to convey extremely high prevalence rates in 'hot spots'. ${ }^{14}$ Even hot spots along the same road a few kilometres apart can have surprisingly different rates. For example in Nyanza Province, Kenya, HIV prevalence rates in some towns beside Lake Victoria (eg Homa Bay) are in excess of 30\%, whereas the rate in towns a short way inland (eg Kisii) have rates around 10-15\%. This probably reflects the fact that fishermen are momentarily rich when they bring in a good catch and can afford commercial sex. In Ethiopia, the overall prevalence disguises a marked difference between towns (average 15\%) and rural communities (rates between $0 \%$ and $3 \%$ ). Nowhere is the spread of HIV by truck drivers so evident, and the need to prevent spread to rural people so urgent.

\section{Can cities be made more healthy places?}

The problems faced by cities in the industrialised rich nations overlap to some extent with those in poorer countries, but the methods of dealing with these problems are very much determined by resources. In the rich nations money can be found for a preventive approach, whereas in the poor it is more a matter of responding to potentially catastrophic situations. The final section of this paper touches on some of the approaches that are being adopted in the two contrasting worlds in which we currently live.

\section{Improving urban health in rich western countries}

Recent concerns about the health consequences of the urban way of life have spurred town planners and public health officials to work more closely together. There are increasing efforts to design cities and communities that promote and support the pursuit of physical and mental health. ${ }^{15,16}$ One of the main problems being tackled is lack of exercise and the consequent increase in problems such as obesity and associated diseases (hypertension and type 2 diabetes) emerging at ever younger ages. In Britain, only $16 \%$ of urban journeys are walked or cycled, compared with $35 \%$ to $45 \%$ on the European continent. ${ }^{17}$ There is emerging evidence that cities which encourage walking and cycling over car use have better health statistics. This supports movements to create new communities according to the principle of 'densification' - having a critical mass of facilities within walking distance. ${ }^{15,18}$

The continued growth of cities in Europe is partly due to rural-urban migration and partly due to an influx of migrants from less developed countries. Urbanisation leads to great inequalities among different ethnic population groups in many ways, not least risk factors for health (poverty, cultural differences, close contact with recent immigrants). Issues of cultural sensitivity and awareness of demographic change need to be incorporated into the health agenda.

Individual responsibility for health is encouraged and supported through health promotion activities. Successful methods include the dissemination of health information and education through schools and health facilities, together with governmentled public campaigns. A good example of a multi-faceted health campaign is the present drive to stop smoking and passive smoking, by highlighting adverse effects, increasing taxation on cigarettes and developing smoke-free work spaces and public areas. Levels of pollution are being tackled with varying enthusiasm under the looming threat of disaster from global warming. A combination of properly researched data and use of modern technologies (eg catalytic exhaust converters) is achieving success, but such methodologies are not easy to spread to poor countries.

\section{Improving urban health in resource-poor countries}

In developing countries, the fact that urbanisation is usually driven by crisis means it is even more difficult to reverse. The scale and rapidity of the process, often set in conditions of political or administrative instability plus lack of resources, make it almost impossible to address health consequences other than by direct response (Table 4). Mitigation of the negative health impacts of urbanisation should be ideally incorporated into the rehabilitation and development strategies of the individual countries. In practice, the situation is usually one of unplanned expansion and chaos, as anyone who has walked through the plastic slums of an Indian city will know.

One factor common to all the developing countries is the critical shortage of health workers caused by chronic under-investment, the brain drain and the overwhelming workload imposed

Table 3. Typical health problems in rapidly growing cities of resource-poor countries.

1 Infections:

Sexually transmitted disease

HIV/AIDS

Tuberculosis (often as a co-infection with HIV)

Water-borne infections, including typhoid and cholera

2 'Western' lifestyle diseases:

Cardiovascular disease (ischaemic heart disease, stroke, hypertension)

Respiratory infections

Asthma

Chronic obstructive pulmonary disease

Lung cancer

Liver cirrhosis

Obesity

Diabetes mellitus

Mental illness 
by HIV/AIDS. ${ }^{19,20}$ In urban settings, the shortage is exacerbated by ongoing massive increases in population. The World Health Organization's Development Assistance for Health has an increase in human resources capacity as one of the main items on its agenda. ${ }^{21}$

Preventive measures, including upgrading of the infrastructure, are the initial and vital component of communicable disease control. The incidence and impact of infectious diseases are inversely proportional to economic growth, and further improvements should be expected in the medium to long term as the towns become more prosperous.

Pre-planning in disaster-prone areas should do all possible to minimise the economic and social effects on rural populations and thus the need for forced migration. Economic support for smaller towns, and trade policy to decentralise small goods production into small domestic industry units, also contribute to this strategy. Attempts to re-populate rural areas generally have met with limited success. Often a limiting factor is the expense incurred when creating adequate infrastructure to satisfy people who have become used to urban living.

\section{The future}

Many of the conditions described above place human health at risk, and their deleterious effects are likely to become even more pronounced as the gap between the urban rich and poor increases. Reversal of these adverse trends will require effective

Table 4. Approaches to mitigating urban health risks.

\section{Developed countries}

- Health-promoting design by architects and building engineers

- Urban planning to create communities within walking distance of critical services

- Facilities for health as a leisure activity

- Cultural sensitivity and demographic change are part of the health agenda

- Municipal and national policies

- use of pollutants

- smoking and smoke-free areas

- health and safety at work

- green areas and cycle lanes

- Public health promotion campaigns.

Developing countries

- Development aid targeted at improving health (MDGs)

- Increase human resources capacity in the health sector

- Improvements to infrastructure

- Water and sanitation

- Capacity and distribution of healthcare

- Contain rural-urban migration

- Disaster mitigation to reduce the effect on rural livelihoods

- Economic support for smaller towns

- Decentralise goods production into small units

MDGs = Millennium Development Goals. collaboration between many different disciplines - health, urban planning, environment, energy, transportation and others. ${ }^{22}$ Far greater investment will be needed in sanitation, water supply, health facilities and human resources. The humanitarian and economic imperative to make cities healthier should drive the multisectoral collaboration that is essential to overcome the challenges.

\section{References}

1 UN-HABITAT. The state of the world's cities 2001. Nairobi: UN-HABITAT.

2 The Population Reference Bureau. Human population: fundamentals of growth patterns of world urbanisation. www.prb.org/content/... patterns_of_world_urbanisation

3 Stephens C. Urbanisation: the implications for health. Afr Health 1996:18(2):14-5.

4 Garenne M. Migration. Urbanisation and child health in Africa: a global perspective. Paris: L'Institut de Recherche pour le Developpement, 2003.

5 Woods RI, Watterson PA, Woodward JH. Mortality decline in England and Wales, 1861-1921. Pop Studies 1988;42:343-66.

6 Bunnell RE, Dahlberg L, Rolfs R, Ransom R et al. High prevalence and incidence of sexually transmitted diseases in urban adolescent females despite moderate risk behaviours. J Infect Dis 1999;180(5):1624-31.

7 Mangtani P, Jolley DJ, Watson JM, Rodrigues LC. Socioeconomic deprivation and notification rates for tuberculosisin London during 1982-91. BMJ 1995; 310(6985):963-6.

8 Bejean S, Sultan-Taieb H. Modelling the economic burden of diseases imputable to stress at work. Eur J Health Econ 2004 Sep 28.

9 Telegraph.co.uk 25 August 2003.

10 Godfrey R, Gill G. Progress, problems and urban change. In Parry E, Godfrey R, Mabey D, Gill G (eds), Principles of medicine in Africa, 3rd edn. Cambridge: Cambridge University Press, 2004.

11 Cleland J, van Ginneken J. Maternal education and child survival in developing countries: the search for pathways of influence. Soc Sci Med 1988;27(12):1357-68.

12 Harpham T, Stephens C. Urbanization and health in developing countries. World Health Stat Q 1991;44(2):62-9.

13 African Population and Health Research Centre. Population and health dynamics in Nairobi's informal settlements. Nairobi: APHRC, 2002.

14 Buve A, Bishikwabo-Nsarhaza K, Mutangadura G. The spread and effect of HIV-1 infection in sub-Saharan Africa. Lancet 2002;359(9322) 2011-7

15 Landry C. Health and urban design. Riding the rapids: urban life in an age of complexity. London: RIBA Enterprises Publishing, 2004.

16 World Health Organization. Healthy cities and urban governance. www.euro.who.int/healthy-cities/Urban HealthTopics

17 Pucher J, Dijkstra L. Promoting safe walking and cycling to improve public health: lessons from the Netherlands and Germany. Am J Pub Health 2003; 93:1509-16.

18 Tellnes G. Integration of nature-culture-health as a method of prevention and rehabilitation. International Conference on Culture and Health. Paris: UNESCO, 1995.

19 Chen L, Evans T, Anand S, Boufford JI et al. Human resources for health: overcoming the crisis. Lancet 2004;364:1984-90.

20 World Health Organization. Macroeconomics and health. Geneva: WHO, 2003.

21 Michaud, C. Development assistance for health: recent trends and resource allocations. Geneva: WHO, 2003.

22 Moore M, Gould P, Keary BS. Global urbanisation and impact on health. Int J Hyg Env Health 2003;206(4-5):269-78 